\title{
ESCOLA, CURRÍCULO E FORMAÇÃO DOCENTE: DESAFIOS NA CONTEMPORANEIDADE
}

\author{
SCHOOL, CURRICULUM AND TEACHING TRAINING: CHALLENGES IN \\ CONTEMPORARY
}

\author{
ESCUELA, CURRICULUMY FORMACIÓN DOCENTE: DESAFÍOS EN LA \\ CONTEMPORANEIDAD
}

Joelson Alves Onofre *

jaonforecp@yahoo..com.br

* Universidade Estadual de Feira de Santana, Feira de Santana, Bahia - Brasil

\begin{abstract}
Resumo
O presente texto propõe uma reflexão sobre a escola, currículo e formação docente na contemporaneidade, trazendo à baila questões problematizadoras. Alguns questionamentos emergem dessa proposta: para quê e a quem a escola serve? Que currículo e formação docente estão se construindo? A partir das proposições apresentadas, surgem indagações relevantes apoiadas no diálogo com os teóricos da educação. O artigo é resultado de pesquisa bibliográfica cuja finalidade foi pensar acerca do papel da educação numa sociedade em constantes mudanças. $\mathrm{O}$ itinerário teórico-reflexivo objetivou pensar a escola, o currículo e a formação docente numa perspectiva de reinvenção da educação.
\end{abstract}

Palavras-chave: Currículo, Escola, Formação docente, Práxis pedagógica.

\begin{abstract}
This text proposes a reflection on the school, curriculum and faculty training in contemporary, bringing to the relevant issues. Some questions emerge from this proposal: what is the school for? What curriculum and faculty training are building? From the propositions presented, relevant inquiries are supported in dialogue with educational theorists. The article is a result of bibliographical research whose purpose was to think about the role of education in a society in constant change. The theoreticalreflective itinerary aimed to think of the school, curriculum and faculty training in a perspective of reinventing education.
\end{abstract}

Keywords: Curriculum, School, Teaching formation, Pedagogical Praxis.

\section{Resumen}

El presente texto propone una reflexión sobre la escuela, currículo y formación docente en la contemporaneidad, trayendo a la baila cuestiones problematizadoras. Algunos cuestionamientos emergen de esta propuesta: ¿para qué y a quién sirve la escuela? ¿Qué currículo y formación docente se están construyendo? A partir de las proposiciones presentadas, surgen indagaciones relevantes apoyadas en el diálogo con los teóricos de la educación. El artículo es el resultado de la investigación bibliográfica cuya finalidad fue pensar acerca del papel de la educación en una sociedad en constantes cambios. El itinerario teórico-reflexivo objetivó pensar la escuela, el currículo y la formación docente en una perspectiva de reinvención de la educación.

Palabras clave: Currículo, Escuela, Formación docente, Práxis pedagógica. 


\section{INTRODUÇÃO}

O objetivo deste artigo é refletir acerca do papel da escola na contemporaneidade, bem como do currículo e a formação docente. Nesse sentido, propõe algumas considerações concernentes à articulação de três elementos fundamentais: educação, sociedade e práxis pedagógica. Ora, não de pode pensar a educação sem a sociedade e nem a sociedade sem a educação. A práxis é o eixo integrador entre esses dois elementos.

Pensar a escola é imaginar que sua existência é importante para a sociedade, por mais que queiramos discutir os prós e contras. Assim como as famílias desempenham, como instituição, um papel significativo, as escolas como "reprodutoras" de conhecimentos produzidos em seu interior e fora dele, também são responsáveis por inovações e mudanças.

Analisa-se, também, a formação docente a partir dos pressupostos da educação e as consequentes transformações que ocorrem no campo educacional. Apesar da ação docente, muitas vezes, sofrer uma "crise" diante de tantos modelos pedagógicos oferecidos, o que deve nortear o fazer pedagógico é justamente a aprendizagem mútua baseada no trabalho colaborativo e participativo.

\section{EDUCAÇÃO: INCERTEZAS E DESAFIOS PARA FORMAÇÃO DOCENTE}

Estamos presenciando uma época em que a educação não traz mais as certezas de que tanto professávamos. Diante das atuais inovações no ensino, ocasionadas pela atual demanda social, muitos princípios ditos necessários ou que são considerados referenciais à educação, estão sendo esquecidos. Sabemos o quanto a sociedade tem evoluído e sua consequente "modernização" tem preocupado sobremaneira a dimensão da prática pedagógica. Considerando o acelerado processo de atualização, os princípios que devem nortear a prática docente são aqueles que conseguem, apesar dos desafios impostos por um modelo vigente, transformar a realidade educacional no que se refere à postura do educador perante tantas mudanças oriundas de uma globalização que devora e exclui tantas pessoas, que inviabiliza o acesso a uma educação de qualidade.

Ao pensar a prática pedagógica como um elemento a ser repensado a cada momento, Arroyo (2000) nos apresenta a preocupação de se fazer sempre uma retomada ao nosso ofício de Mestre. O autor cita "ofício" como atividade intrínseca do educador, sua prática e atuação, sua memória e valores. O que se coloca em questão é justamente esse "ofício" que muitas vezes está fora de foco. Parece-nos que os educadores (salvo exceções) não equiparam ainda sua caixa de ferramentas. Nossa sociedade, com toda 
a sua complexidade, ainda assim dever ser responsável por uma educação que entenda o ser humano e acolha sua cultura e identidade. A razão instrumental não está descartada, mas é de suma importância que se opte por uma razão comunicativa, onde alunos e educadores construam e produzam conhecimento.

Há de se considerar, portanto, a bagagem cultural e a história de vida do educando. Nosso fazer pedagógico é um fazer concreto, voltado para sujeitos concretos e não abstratos. No entanto, ainda convivemos com resquícios de uma educação retrógrada, sem se preocupar com o homem em sua completude. Urge da escola um olhar voltado para os educandos e suas vivências. Nisto consiste o papel da didática na perspectiva de uma prática educativa que possibilite ao aluno inserir-se num projeto histórico, que não será construído apenas pelo educador, mas também pelo educando e por todos os setores da sociedade.

Ora, a escola deve tornar-se uma comunidade de aprendizes mútuos, onde os saberes sejam vivenciados de forma consciente e prazerosa. Por causa de um modelo educacional imposto por um sistema capitalista que exige qualificação constante de quem deve oferecer o melhor, a educação precisa repensar urgentemente seu papel social. Temos um longo caminho a percorrer no sentido de compreender que podemos fazer a diferença na educação e na vida dos educandos. Diante disso, a adesão às propostas inovadoras no que diz respeito as mais modernas práticas educativas não garante um significativo trabalho pedagógico junto aos educandos.

A opção por uma educação libertadora deve considerar a atuação do educando como sujeito de um processo educacional. Somos aprendizes e como tal, possuímos saberes, dominamos técnicas e estreitamos relações. Para tanto, é necessário que nossa consciência não subtraia nossa prática. Que ela seja fruto de uma madura atitude, despertando tanto nos educandos quanto nos educadores a vontade de transformar a própria realidade.

Hoje, testemunhamos uma imensa preocupação em despejar no aluno conteúdos livrescos e necessários para concursos e vestibulares. Esquecemos que, diante de tanta técnica e conteúdo, o educando apreende conhecimentos sem saber aplicá-los à vida. As ferramentas não lhes foram oferecidas. E quando tomam posse desses recursos, tornam-se "práticos", "inertes", não se encontrando como sujeitos de sua própria realidade. Nossa prática pedagógica ainda se encontra distante da realidade desafiadora dos alunos e suas implicações. Implicações essas que devem surgir a partir da realidade do aluno, da sua cultura e identidade.

Toda ação docente possui uma intencionalidade e cada professor constrói seu percurso epistemológico, ou seja, deve reconhecer que “o conhecimento científico é provisório, jamais acabado 
ou definitivo. É sempre tributário de um pano de fundo ideológico, religioso, econômico, político e histórico" (TESSER, 1994, p. 92). Por entendermos que a epistemologia é o estudo do conhecimento, no âmbito da formação docente, faz-se necessário que cada professor faça escolhas acertadas no que se refere ao processo do conhecimento. Nesse sentido, a tendência que mais se aproxima do que pensamos ser o processo educativo é a progressista histórico-crítica por possibilitar uma maior autonomia ao sujeito (aluno) no sentido deste se apropriar dos conhecimentos científicos socialmente válidos e relacioná-los com a realidade social. Nessa abordagem não se descarta a historicidade do sujeito nem tampouco a capacidade que este tem de criticar a própria realidade. Esse exercício só se efetiva mediante a dialética e a prática social. Acreditamos ser emancipadora essa tendência, pois viabiliza que as questões da educação sejam encaradas a partir da realidade social que se configura como complexa e repleta de conflitos.

\section{A ESCOLA QUE TEMOS E A QUE QUEREMOS}

O surgimento da escola e o processo de escolarização são fenômenos recentes. Nossa aprendizagem se deu por experiências diversas e a escola ainda não existia da forma como a conhecemos hoje. Somos condenados a aprender e a maioria dos conhecimentos que adquirimos não veio da escola (CANÁRIO, 2006).

Em reflexões anteriores acerca da instituição escolar, sinalizamos que a escola deve pensar criticamente o currículo e suas dimensões excludentes.

A instituição escolar insere-se no tecido social e por fazer parte integrante nesse contexto, assume uma dimensão política que se reflete na sala de aula. Essa realidade deve proporcionar à escola uma análise crítica dos instrumentos de poder que muitas vezes encontram-se subjacentes na formação do currículo. Esses instrumentos, por vezes, inviabilizam a formação de um currículo plural, baseado na diversidade e nas diferenças, isto é, a cultura erudita, disponibilizada para poucos, dita as regras e potencializa aquilo que poderíamos denominar "currículo imposto", organizado e elaborado por especialistas em gabinetes fechados (ONOFRE, 2008, p. 106).

$\mathrm{Na}$ perspectiva de pensar o currículo e como o conhecimento é construído, Young (2009) contribui para essa discussão destacando dois tipos de conhecimentos que considera importante serem diferenciados: o conhecimento dos poderosos e o conhecimento poderoso. O conhecimento dos poderosos é definido por quem detém o conhecimento. É fácil perceber essa realidade no que ser refere à 
universidade. Muitos conseguem ingressar nos cursos universitários porque tiveram e ainda têm acesso a determinados conhecimentos que a minoria desprivilegiada não tem. $\mathrm{O}$ conhecimento poderoso, segundo Young (2009), seria o conhecimento especializado, adquirido no ambiente escolar, mas que necessita sempre de uma nova leitura de mundo. Na visão do autor, a escola exerce a função de "transmitir" conhecimento poderoso.

Ressaltamos que a escola necessita ressignificar conceitos relativos às metodologias, o que ensina e como ensina e debater sobre essas questões. São imperativos que se apresentam às realidades escolares, mas que se não forem refletidos, certamente trarão limitações à compreensão do verdadeiro papel da instituição escolar.

Nossa intenção não é discorrer sobre a "missão" salvífica da escola, até porque acreditamos não ser esse o verdadeiro sentido. Seu papel não se restringe a redimir a sociedade, alunos, pais. Além da responsabilidade na transmissão de conhecimento, focar atenção na bagagem cultural dos alunos, não excluindo os saberes provenientes de outros espaços de aprendizagem que não os formais, é uma de suas atribuições.

A escola que temos prioriza conteúdos e não trabalha no sentido de dar sentido e significado a eles.

A escola que temos é fortemente marcada pelo caráter instrumentalizador, conteudista, academicista [...]. Carece primar pela democratização do conhecimento, investindo em múltiplos saberes, respeitando e acolhendo os conhecimentos dos alunos e suas perspectivas de aprendizagem (ONOFRE, 2014, p. 104).

Essa possibilidade de análise reflexiva, a nosso ver, encontra-se no currículo e na maneira como ele é pensado e concretizado. Assim, um aspecto que consideramos imprescindível discutir, refere-se à reinvenção do currículo escolar. Nessa perspectiva, reinventá-lo e repensá-lo exige refletir acerca das demandas dos sujeitos, de suas vivências e sensibilidades (ONOFRE, 2008).

Pensar o currículo pressupõe, enquanto educadores, estarmos atentos às diversas realidades culturais e sociais dos nossos jovens e considerá-los agentes ativos no processo educacional. "Como os vemos? Como nos obrigam a vê-los? Enfim, somos convocados a repensar o que ensinamos, o que aprendemos. Isso obriga-nos a rever nossas práticas pedagógicas, nossas metodologias de ensino e os conteúdos de nossa docência”. (ONOFRE, 2008, p. 106)

Compreender o currículo como espaço de disputa, intenções, tensões e conflitos é fundamental para que se tenha uma noção das possibilidades outras em que se pode, a partir de uma leitura crítica dos 
conteúdos trabalhados nas escolas, perceber as artimanhas das intencionalidades presentes nas ações curriculares.

[...] Tudo na escola é pensado para um padrão de normalidade em que o aluno desejado é o que serve de modelo para avaliar outros alunos. Quando os outros não conseguem atingir os índices de aprendizado, são rotulados como incapazes, atrasados, lentos (ONOFRE, 2008, p. 107).

As discussões teóricas sobre o currículo têm possibilitado uma gama de conhecimentos a respeito da compreensão da efetividade ou não do currículo. Muitos estudiosos têm se debruçado e contribuído para o entendimento do que significa currículo numa perspectiva crítica e pós-crítica (SILVA, 1995, 1999; SANTOMÉ, 1995; SACRISTÁN, 1995; CANDAU, 2008; MOREIRA; MACEDO, 2001). Há de se refletir sobre a possibilidade de se reformar o pensamento e criticar a fragmentação do ensino. Na perspectiva, a sala de aula é o lugar ideal para se iniciar uma reforma de mentalidade. A educação deve priorizar um pensamento integrador sem deixar de considerar as especificidades de alunos e professores. O professor deve saber dominar competências para resolver os problemas que vão surgindo em sua prática pedagógica e isto acontece quanto este desenvolve habilidades cognitivas, ou seja, nós educadores precisamos assumir posturas mais enérgicas e críticas em relação ao que aprendemos e ensinamos. É por isso que consideramos a formação docente uma prioridade.

Não é possível pensar o currículo sem levar em conta que professores precisam se atualizar e a formação é o caminho ideal para isso ocorrer. As reflexões sobre currículo devem fazer parte da formação continuada dos docentes, numa perspectiva de concebê-lo como uma proposta de trabalho colaborativo. Acreditamos que o currículo não deve restringir-se a conteúdos predeterminados. Nesse sentido, nada de conteúdos rígidos, estanques, sem sentido. O currículo deve fazer sentido para aluno e professor. A escola é o lugar onde a formação integral do aluno é o mais importante e, nesse sentido, não se constitui como o único lugar de aprendizagem. A crítica que apontamos refere-se à existência de uma escola que continua priorizando saberes hegemônicos e totalmente distantes da realidade dos alunos.

A homogeneização e padronização que as escolas ainda praticam em seus espaços, acabam por descaracterizar os processos de aprendizagem que visam acolher todos os saberes oriundos das experiências dos educandos, bem como suas visões de mundo e da vida. A escola, enquanto espaço de descobertas, troca de experiências e aprendizados diversos, necessita abrir-se para a realidade dos educandos, da comunidade etc. Essa realidade se traduz naquilo que consideramos de suma importância para a complementação do currículo escolar: a inserção de saberes, vivências e manifestações culturais que acontecem fora dos muros escolares (ONOFRE, 2008, p. 107) 
O currículo deve possuir uma dimensão libertadora e política. Nessa perspectiva, se traduz em ato libertador, pois possibilita que façamos uma leitura crítica da sociedade atual, considerando as complexas relações de poder que se estabelecem entre dominadores e dominados. Dada essa realidade, o currículo entendido como construção coletiva pressupõe e exige do professor uma postura crítica diante dos acontecimentos. A educação é um ato político e, portanto, não há educação neutra, ou seja, o professor deve se questionar a todo o momento a quem ele está servindo. Como docentes, somos impelidos a nos certificarmos das nossas intenções curriculares. Dito isto, o currículo pode contribuir para uma educação que seja de fato política, que permita uma leitura criteriosa da sociedade e das complexas relações de poder existentes entre os sujeitos envolvidos no processo educativo.

Defendemos que a escola não pode isentar-se de propor novas metodologias de ensino a seus educandos, mas que tais ensinamentos sejam, de fato, significativos e possam dialogar com os conhecimentos trazidos pelos educandos a partir das experiências extramuros da escola.

Canário (2006) considera que para a escola pensar sua educação escolar (formal) há de se ter como referência a educação não-escolar (não formal). Nessa perspectiva, a escola, debruçando-se sobre o conhecimento dos processos da educação não-formal certamente terá condições de analisar a educação formal, bem como suas situações de aprendizagens.

O mesmo autor aponta três razões pelas quais podemos considerar a escola obsoleta. A primeira diz respeito ao monopólio educativo da escola. Detentora desse monopólio, não dialoga com os processos não-formais de educação e assim subestima a capacidade de socialização que outras instituições têm no processo de aprendizagem.

A segunda razão refere-se à associação que fazemos entre escola e ensino. As escolas ainda estão preocupadas com a lógica do ensino e não focam atenção nos processos de aprendizagem. Isso ocorre porque estamos habituados a pensar na perspectiva do professor como "transmissor" do conhecimento e não nas aprendizagens significativas que emergem das relações estabelecidas em sala de aula. Os educandos são aprendentes e, portanto, autônomos do próprio processo de aprender.

Por fim, a terceira razão da "obsoletização" da escola, apontada pelo autor, está nos modos de organização e nos métodos de trabalho que a escola assume. A repetição e a transmissão de conteúdos, sem articulação com os objetivos propostos, conferem à escola uma dinâmica muito próxima da lógica da linha de montagem, onde o conhecimento é transmitido de forma mecânica e sem significado.

Consideramos que a escola, concernente às mudanças, necessita inserir-se no contexto social mais amplo e propor novas maneiras de pensar a educação. 


\section{CURRÍCULO COMO CAMPO DE ANÁLISE}

Em relação ao currículo, cabe-nos uma reflexão sobre como estamos trabalhando os conteúdos curriculares em nossas salas de aula. Estamos dando a devida atenção à realidade da escola e dos alunos, seus históricos de vida, desejos e sonhos? Para um melhor aprendizado, faz-se necessário um currículo que dialogue com a realidade social dos alunos, destacando suas demandas, urgências, modos de ser e aprender. Talvez o desinteresse do aluno esteja associado à questão de a escola não conseguir acompanhar as ferramentas tecnológicas atuais. Muitas vezes as aulas, os conteúdos estão totalmente desconectados de suas reais necessidades. Com isso não estamos de forma alguma culpando o professor e sim, asseverando que há uma relação desses acontecimentos com a organização curricular e escolar, pois é na escola que o aluno tem contato com o conhecimento, com as discussões, com noções de cidadania e civilidade.

Quando nos referimos ao currículo, estamos no campo da disputa de poder, como bem destaca Tomaz Tadeu da Silva (2010), e de referenciais que se constroem considerando o conhecimento hegemônico e determinado a partir de uma única história. A complexidade com a qual tratamos o currículo revela-nos as sutilezas das determinações e conteúdos solidificados que permeiam os discursos e as políticas curriculares em nossa realidade educacional. Implantar um currículo que dê conta do direito à formação básica plena, conforme preconiza a LDBN, exige-nos, portanto, mais que o cumprimento de um marco legal, exige-nos que a educação seja de fato garantida a todos os cidadãos. A educação é direito de todos e dever do Estado (BRASIL, 1988). Um currículo na perspectiva da formação plena deve assegurar o desenvolvimento da capacidade de aprender de cada aluno por meio da leitura e escrita, do domínio das operações básicas, compreensão do ambiente social, da política e da técnica, das artes, da cultura e dos valores, dos vínculos familiares, assim como dos laços de solidariedade e tolerância. Assimilar não somente os conteúdos curriculares específicos de cada componente, mas articulá-los com a vida, para uma formação plena, onde o exercício da autonomia intelectual e do pensamento crítico do aluno esteja em evidência.

Conceber o currículo como análise crítica da educação, pressupõe pensá-lo a partir de outras perspectivas e com isso orientar uma reflexão que possibilite confrontar as narrativas hegemônicas com os novos alinhamentos teóricos que surgem das experiências das minorias, ou seja, das culturas e saberes não reconhecidos no campo curricular oficial. Com isso, defendemos um currículo multicultural voltado para a emergência de novas rotas epistemológicas, onde se vislumbre a presença efetiva dos saberes tradicionais oriundos das diversas culturas não evidenciadas no currículo. Corroborando com Canen 
(2010, p. 179), compreendemos o currículo como espaço onde de deva destacar concretamente a diversidade de saberes e práticas culturais:

[...] Ainda que o determinante de classes sociais permaneça na análise curricular, a necessidade de se compreender o currículo como uma seleção cultural impregnada por uma visão de mundo branca, masculina, heterossexual e eurocêntrica passa a ser central em estudos curriculares, que buscam pensar em currículos alternativos, multiculturais.

Os currículos alternativos, mencionados pela autora, precisam ser problematizadores de análises críticas relativas aos conteúdos curriculares impostos. Pensar em currículos multiculturais não garante sua efetiva implementação, haja vista que ainda nos deparamos com desafios no campo curricular. A construção teórica dessa área de conhecimento há décadas vem afirmando uma sobreposição dos saberes hegemônicos em detrimento dos saberes das minorias e com isso perpetuado ideias extremamente conservadoras.

Dito isto, nossa intenção com o presente texto fora provocar uma reflexão apontando algumas ideias relacionadas à educação, currículo e formação docente, tentando trazer à baila o quão complexa é a interface entre esses três elementos para se pensar a educação na contemporaneidade.

\section{CONSIDERAÇÕES FINAIS}

A importância de se repensar a escola na contemporaneidade foi o que motivou nossas proposições, articulando educação, sociedade e práxis pedagógica. Essa tarefa torna-se desafiadora e urgente, haja vista que tais elementos trazem em seu bojo complexidades que de certa forma instigam o docente a pensar seu fazer pedagógico.

As reflexões sobre a escola carecem de uma análise crítica substancial que não considere apenas o papel de transmissora de conhecimento, mas o de propiciadora de uma relação dialógica com a sociedade, a educação, a prática docente. Nessa perspectiva, urge considerar sua relevância na sociedade e a importância de sua existência. Se a educação conseguir ressignificar sua função de possibilitadora do exercício da cidadania a crianças, jovens e adultos, acolhendo, respeitando os diversos saberes, oriundos de espaços não formais de aprendizagem e articulando esses saberes com a vida, já terá cumprido de forma bastante eficaz seu papel. 


\section{Referências}

ARROYO, Miguel Gonzalez. Ofício de Mestre: imagens e auto-imagens. Petrópolis: Vozes, 2000.

BRASIL. Constituição da República Federativa do Brasil. Brasília, DF: Senado Federal, 1988. Disponível em: < http://www.planalto.gov.br/ccivil_03/constituicao/co nstituicaocompilado.htm>. Acesso em: 20 abr. 2017.

CANÁRIO, Rui. A escola tem futuro? Das promessas às incertezas. Porto Alegre: Artmed, 2006.

CANDAU, Vera Maria. Multiculturalismo e educação: desafios para a prática pedagógica: In: MOREIRA, Antonio Flávio; CANDAU, Vera Maria (Orgs.). Multiculturalismo: diferenças culturais e práticas pedagógicas. Petrópolis: Vozes, 2008. p. $13-37$.

CANEN, Ana. Sentidos e dilemas do multiculturalismo: desafios curriculares para o novo milênio. In: LOPES, Alice Casimiro; MACEDO, Elizabeth (Orgs.). Currículo: debates contemporâneos. 3. ed. São Paulo: Cortez, 2010. p. 174-195. (Série Cultura, Memória e Currículo)

MOREIRA, Antonio Flávio; MACEDO, Elizabeth Fernández de. Em defesa de uma orientação cultural na formação de professores. In: MOREIRA, Antônio Flávio; CANEN, Ana (Orgs.). Ênfases e omissões no currículo. Campinas: Papirus, 2001.

ONOFRE, Joelson Alves Onofre. Repensando a questão curricular: caminho para uma educação antiracista. Práxis Educacional. Vitória da Conquista, v. 4, n. 4 p. 103-122 jan./jun. 2008.

A Lei 10.639/03 e seus desdobramentos em uma escola quilombola. 171 f. 2014. Dissertação (Mestrado) - Faculdade de Educação, Universidade Federal da Bahia, Salvador, 2014.
SACRISTÁN, J. Gimeno. Currículo e diversidade cultural. In: SILVA, Tomaz Tadeu da; MOREIRA, Antonio Flávio (Orgs.). Territórios contestados: o currículo e os novos mapas políticos e culturais. Petrópolis: Vozes, 1995. p. $82-113$.

SANTOMÉ, Jurjo Torres. As culturas negadas e silenciadas no currículo. In: SILVA, Tomaz Tadeu da. (Org.). Alienígenas na sala de aula: uma introdução aos estudos culturais em educação. Trad. Tomaz Tadeu da Silva. Petrópolis: Vozes, 1995.

SILVA, Tomaz T. O currículo como fetiche: a poética e a política do texto curricular. Belo Horizonte: Autêntica, 1999.

Documentos de identidade: uma introdução às teorias do currículo. 3. ed. Belo Horizonte: Autêntica, 2010.

Currículo e identidade social: territórios contestados. In: Alienígenas na sala de aula: uma introdução aos estudos culturais em educação. Petrópolis: Vozes, 1995.

TESSER, Gelson João. Principais linhas epistemológicas contemporâneas. Educ. rev. n.10 Curitiba Jan./Dec. 1994. p. 91-98.

YOUNG, Michel. Para que servem as escolas? In: PEREIRA, Maria Zuleide da Costa; CARVALHO, Maria Eulina Pessoa de: PORTO, Rita de Cássia Cavalcanti. (Orgs.). Globalização, interculturalidade e currículo na cena escolar. Campinas: Alínea, 2009. p. 39-54. 
Recebido em: 20/09/2017

Aceito em: 16/11/2017

Endereço para correspondência:

Nome: Joelson Alves Onofre

Email: jaonforecp@yahoo.com.br

cc) (i)

Esta obra está licenciada com uma Licença $\underline{\text { Creative }}$

Commons Atribuição 4.0 Internacional. 